\title{
Clinical and Demographic Profile of Inflammatory Bowel Disease Patients in a Reference Center of São Paulo, Brazil
}

This article was published in the following Dove Press journal: Clinical and Experimental Gastroenterology

\author{
Tarcia Nogueira Ferreira \\ Gomes (D) \\ Fabio Silva de Azevedo (ID) \\ Marjorie Argollo \\ Sender Jankiel Miszputen \\ Orlando Ambrogini Jr \\ Disciplina de Gastroenterologia, Escola \\ Paulista de Medicina, Universidade \\ Federal de São Paulo (UNIFESP), São \\ Paulo, Brazil
}

Background: Crohn's disease (CD) and ulcerative colitis (UC) are chronic inflammatory diseases of the gastrointestinal tract with an increasing incidence in developing countries.

Purpose: To report clinical and demographic data of $\mathrm{CD}$ and $\mathrm{UC}$ at a referral center for inflammatory bowel disease (IBD) in São Paulo.

Patients and Methods: We conducted a retrospective cross-sectional study on adult patients with established IBD. Demographic and clinical data were obtained by medical records analysis from the IBD Outpatient Clinic of EPM-UNIFESP, from October 1997 to October 2017.

Results: Of 658 patients included, 355 had UC (54\%) and 303 had CD (46\%). UC was more prevalent in women than $\mathrm{CD}(219[61.7 \%]$ vs $152[50.2 \%], \mathrm{p}=0.003)$. The median time between the onset of symptoms and diagnosis was 13 (5-38) months, with a longer duration for CD patients. CD mostly affected the ileocolonic location (47.9\%). CD patients with stricture, fistula and/or perianal disease $(213 / 303,70.3 \%)$ were younger at diagnosis, had a longer disease duration, higher rates of corticosteroid, immunomodulatory, and biological therapy, hospitalization, and referral to surgery, compared to patients without complication. Extensive colitis was the most common extension of UC (50.6\%), which was more frequently associated with younger age at diagnosis, hepatobiliary disease, increased need for hospitalization, higher use of immunomodulatory, and biologic therapy, compared to patients with less extensive disease. In the last 5 years, CD patients were more frequently on biologic and/or immunomodulatory (70.9\%) therapy, and UC patients often received salicylates (78.1\%) and immunomodulatory (28.1\%) treatments. There was a consistent reduction in salicylate usage for CD in the last 5 years compared to the total period of follow-up.

Conclusion: Despite the increasing incidence, we highlight the diagnostic delay and a more complicated CD and extensive UC in this cohort, reflecting a high need for immunomodulatory and biological treatment, hospitalization, and surgery.

Keywords: Crohn's disease, epidemiology, inflammatory bowel disease, ulcerative colitis

\section{Introduction}

Inflammatory bowel diseases (IBD) are characterized by chronic and recurrent inflammation of the gastrointestinal tract and are classified into two main types: ulcerative colitis (UC) and Crohn's disease (CD). ' Their etiology is uncertain, although studies suggest that they have a multifactorial origin, involving genetic susceptibility, environmental factors, gut microbiota, and innate and adaptive immunity. ${ }^{2-4}$ IBD are considered a public health issue worldwide because of their long term incurable conditions, which imply significant damage to health-related
Correspondence: Tarcia Nogueira Ferreira Gomes

Rua Percílio Neto, I3I, Vila Gumercindo, CEP 04 I 3 I-080, São Paulo-SP, Brazil Tel +55 II 9499I 3883

Email tarcia.nogueira@gmail.com
Clinical and Experimental Gastroenterology 2021:14 91-102 
expenses and quality of life. ${ }^{5-9}$ In North America and Europe, with the highest worldwide IBD prevalence, it is estimated that over 1.5 and 2.5 million people, respectively, live with IBD. ${ }^{10-12}$ Although this prevalence is high, the incidence appears to be stable or even decreasing. ${ }^{10}$

Epidemiological studies in developing countries from Asia, South America, and Africa revealed an increasing incidence of IBD in the last 20 years, despite a low prevalence, which has been explained by the change in environmental factors (related to industrialization), wider access to healthcare, and cases registry. ${ }^{10,11,13}$

Brazil is the most populated South American country, with over 200 million people, with diverse genetic backgrounds, secondary to the miscegenation of indigenous people, Europeans, Africans, and Asians, in over 500 years of its history. ${ }^{14}$ Such diversity varies according to the country region, with a large genetic burden of Europeans in the South and Southeast regions of Brazil. ${ }^{14}$

Moreira et al identified 162,894 people with IBD between 2008 and 2017 in Brazil, with UC being the most prevalent (59\%) in contrast with CD (41\%). The prevalence of IBD was 80 per 100,000 inhabitants, and there was an evident increase in new cases over that period. Places with higher human development indexes, urbanization, sanitation, and Caucasian population have a higher prevalence of IBD, with São Paulo state presenting the highest in Brazil. ${ }^{15}$ Gasparini et $\mathrm{al}^{16}$ found a prevalence of 52.6 cases of IBD per 100,000 inhabitants and an incidence of 13.3 cases per 100,000 inhabitants per year, between 2012 and 2015, in the state of São Paulo. These numbers were higher than those found by Victoria et al, ${ }^{17}$ evaluating the midwestern of São Paulo state, between 1986 and 2005. Results showed a prevalence of 22.61 cases per 100,000 inhabitants and 7.98 new cases of UC and CD per 100,000 per year. Thus, data suggest an increasing prevalence and incidence in this region, with similar incidence rates reported in European and North American countries. Considering that incidence in developed countries shows stability (or even a slowdown rate), ${ }^{10}$ it is possible to estimate that, sometime in the future, the prevalence of IBD in Brazil can match that of these countries.

Identification of the clinical and epidemiological profile of IBD patients can help recognize potential pathogenic pathways of gut inflammation and suggest effective interventions on human, diagnostic, and therapeutic resources aimed to improve this population's quality of life. In Brazil, there are little data concerning this topic. In addition, no studies have been conducted in São Paulo city, where there is a wide genetic influence of the European population, robust urbanization and industrialization, similar to developed European and North American countries. This study aimed to identify the clinical and epidemiological profile of IBD patients assisted in an IBD reference center in São Paulo city, Brazil.

\section{Patients and Methods Study Design, Participants and Ethical Approval}

This was a cross-sectional, descriptive study. Data were obtained from medical records, which included demographic features, clinical and laboratory tests of IBD patients that were attended to, between 1997 and 2017, by the intestinal disease clinic of Hospital São Paulo, linked to Paulista Medical School from the Federal University of São Paulo. This hospital is a reference center for the care of IBD patients in São Paulo city, with one of the largest numbers of documented cases. IBD patients over 18 years old (age at their last medical appointment) with confirmed disease through clinical, laboratory, endoscopic, histological, and/or radiological evaluation were included, while those with unclassified colitis were excluded, as there were only a few cases. The study complied with the Declaration of Helsinki and was approved by the Federal University of São Paulo Research Ethics Committee (CAAE 60859616.0.0000.5505). Since the data were collected by review of medical charts in a historical cohort, without any further contact with the subject, we obtained the informed consent of patients who presented to a clinical appointment in the period of data collection only, as recommended by the local ethics committee. The researchers preserved the confidentiality and privacy of the study's candidates.

\section{Study Variables and Statistics}

We studied and compared patients with $\mathrm{CD}$ and UC, regarding the following variables: follow-up (attendance to consultation in the last five years and incidence rate of IBD per five-year period); demographic characteristics (sex, age, race, city residence, and schooling); and clinical data (family history of IBD, Montreal classification, ${ }^{18}$ time between symptom onset and diagnosis, extraintestinal manifestations, need for hospitalization, pharmacological, and surgical treatment). 
Descriptive analysis included absolute and relative frequencies for categorical variables. Quantitative continuous variables with normal distribution were described as means and standard deviations. For those whose normality could not be determined, we described as medians with the first and third quartiles (25th and 75 th percentiles). To compare quantitative variables of normal unpaired distribution, Student's $t$-test for independent samples for two groups was utilized. For unpaired samples that did not assume a normal distribution, the Mann-Whitney test was used for two groups and one-way ANOVA for comparisons between three groups. To compare categorical variables, the chi-square test for independent samples and the equality of proportions test were performed when appropriate. Descriptive levels of $p<0.05$ were considered significant.

\section{Results}

\section{Demographic Characteristics}

Of the 658 patients included, 355 (54\%) had UC and 303 (46\%) had CD. Four hundred ninety-seven patients $(75.5 \%)$ had a medical appointment in the last five years of the study inclusion period, with no statistically significant difference between the groups $(\mathrm{p}=0.558)$.

Of the 658 patients, 371 (56.4\%) were female and 293 $(44.6 \%)$ were male. There were predominately women with UC compared with $\mathrm{CD}(\mathrm{p}=0.003)$.
The mean age recorded at the last visit was $44.2 \pm 16.3$ years (mean \pm standard deviation), ranging from $18-90$ years. There was no significant age difference between the $\mathrm{CD}$ and UC.

Most subjects (77.4\%) lived in São Paulo city, and a greater number of those with $\mathrm{CD}$ came from other cities $(\mathrm{p}=0.046)$.

They were predominantly Caucasian (61.5\%) and mixed-race $(33.8 \%)$ populations, with no statistical difference between UC and CD.

Regarding education level, the majority of the patients had less than 12 years of study and did not complete basic education (early childhood education, elementary school, and high school), with a higher level among individuals with CD than those with UC. Demographic characteristics are detailed in Table 1.

\section{Temporal Analysis}

There was an increase in the incidence rate of UC and CD during the five-year period from 1985 to 1989 until the period from 2000 to $2004(\mathrm{p}<0.05)$. From 2005 to 2009, there was no significant change in relation to the immediate previous five-year period, showing stability in the proportion of new cases over the total number of cases per period (Figure 1). In the final analyzed period, there was a drop in the number of cases in relation to the

Table I Demographic Profile of Inflammatory Bowel Disease Patients in São Paulo City, Brazil

\begin{tabular}{|c|c|c|c|c|}
\hline & Total $(n=658)$ & $C D(n=303)$ & UC $(n=355)$ & $\mathbf{p}$ \\
\hline \multicolumn{5}{|l|}{ Age at diagnosis (years) } \\
\hline Mean \pm SD & $33.8 \pm 14.8$ & $32 \pm 14.5$ & $35.3 \pm 14.9$ & $0.004 *$ \\
\hline \multicolumn{5}{|l|}{ Sex } \\
\hline Female & $37 \mathrm{I}(56.4)$ & $152(50.2)$ & $219(61.7)$ & $0.003 *$ \\
\hline \multicolumn{5}{|l|}{ Residence } \\
\hline São Paulo City & $508(77.4)$ & $224(73.9)$ & $284(80.5)$ & $0.046 *$ \\
\hline \multicolumn{5}{|l|}{ Ethnicity } \\
\hline Caucasian & $402(6 \mid .5)$ & $199(66.1)$ & $203(57.5)$ & 0.157 \\
\hline Mixed-race & $221(33.8)$ & $89(29.6)$ & $132(37.4)$ & \\
\hline African descent & $28(4.3)$ & $12(4)$ & $16(4.5)$ & \\
\hline Asian descent & $3(0.5)$ & $\mathrm{I}(0.3)$ & $2(0.6)$ & \\
\hline Missing data & 4 & 2 & 2 & \\
\hline \multicolumn{5}{|l|}{ Education (years of schooling) } \\
\hline Uneducated and $<12$ years & $348(54)$ & $147(49.3)$ & $201(58.1)$ & $0.026 *$ \\
\hline$\geqq 12$ years & $296(46)$ & $|5|(50.7)$ & $145(4 \mid .9)$ & \\
\hline Missing data & 14 & 5 & 9 & \\
\hline
\end{tabular}

Notes: Quantitative variables: Student's t-test (normal distribution); categorical variables: $\chi^{2}$ test; ${ }^{*} \mathrm{p}<0.05=$ statistical significance.

Abbreviations: CD, Crohn's disease; UC, ulcerative colitis; SD, standard deviation. 


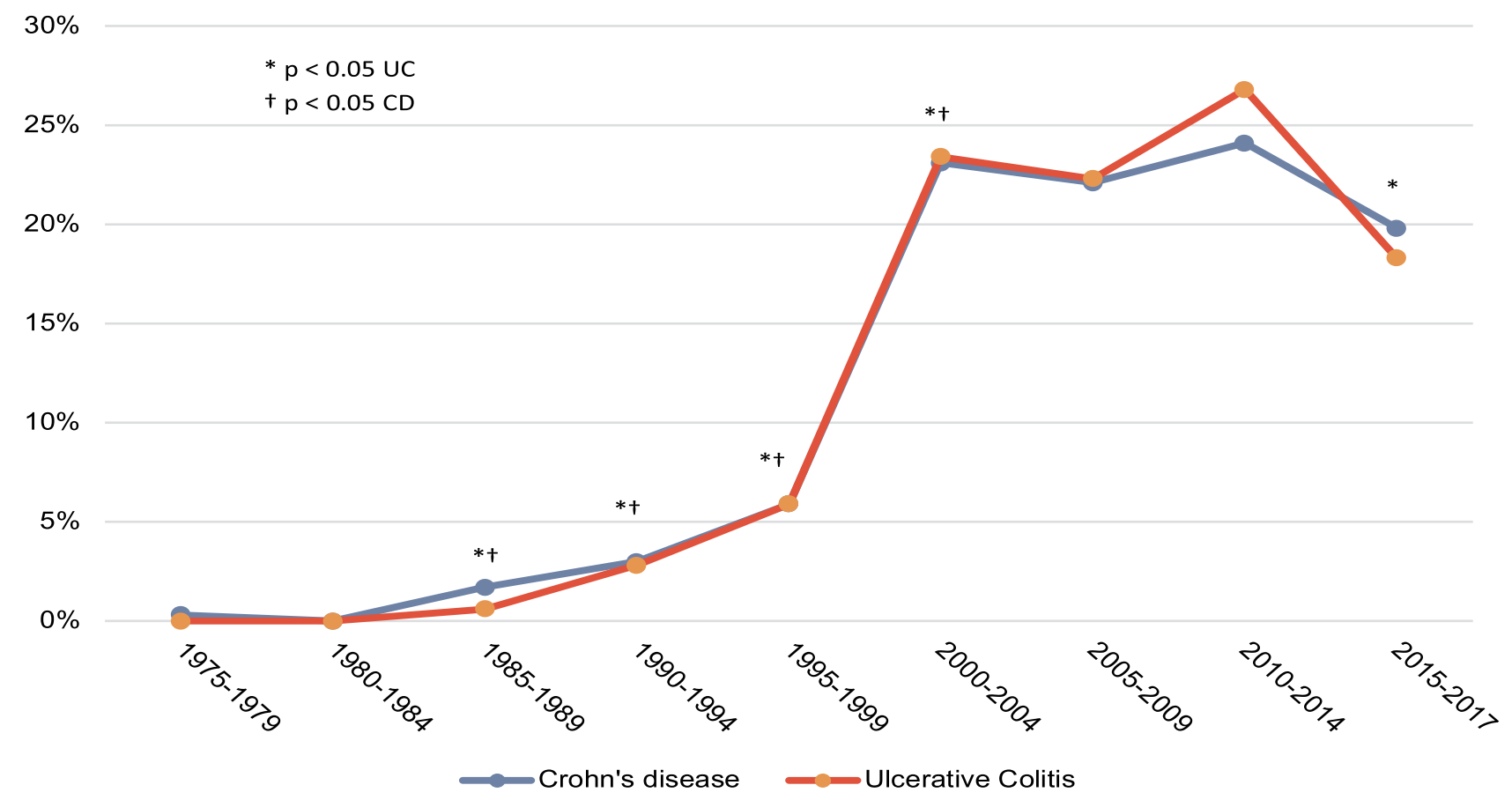

Figure I Incidence rate per 5-year period of Crohn's disease and ulcerative colitis from 1997 to 2017.

Notes: ${ }^{*} p<0.05$ : statistically significant difference compared to the immediate previous period for the same disease for ulcerative colitis; $\dagger p<0.05$ : statistically significant difference compared to the immediate previous period for the same disease for Crohn's disease.

Abbreviations: UC, ulcerative colitis; CD, Crohn's disease.

previous one, possibly because it was a shorter period, with a statistically significant difference only for UC $(\mathrm{p}=0.007)$.

\section{Clinical Profile}

The time interval between the onset of symptoms and definitive diagnosis in CD patients was, in average, 44.8 \pm 69 months, median of 20 (6.5-48) months, and statistically greater than the average of $24.7 \pm 37.8$ months and a median of 11 (4-29) months of those with UC $(p<0.001)$. One hundred and six patients with UC and 62 with $\mathrm{CD}$ did not have, in their medical records, precise data concerning the onset of symptoms, and they were excluded from this analysis. When we analyzed only those diagnosed in the last five years (43 with $\mathrm{CD}$ and 58 with UC), despite the numerical superiority among patients with $\mathrm{CD}$ there was no significant difference in comparison with those with UC (34.1 \pm 62.4 , median of 17 months, vs $21.8 \pm 30.4$, median of 8 months, respectively, $\mathrm{p}=0.291$ ).

Forty-nine (8.2\%) patients reported a family history of IBD, without a difference between CD and UC. A family history of $\mathrm{CD}$ was more common among subjects with $\mathrm{CD}$, and among those with $\mathrm{UC}$, it was also more common to find a family history of $\mathrm{UC}(\mathrm{p}=0.008)$. No information was found regarding the family history of 58 patients $(16.2 \%$ of the total).

The most frequent extraintestinal manifestations were joint, oral, and skin involvement, in both CD and UC. A more significant number of patients with oral manifestations were identified with $\mathrm{CD}$, while hepatobiliary disease prevailed in UC patients. There was no significant statistical difference in joint, skin, and ocular manifestations between the two diseases, despite a slightly higher incidence of these manifestations in $\mathrm{CD}$.

There was a greater need for hospitalization related to IBD among patients with CD than among those with UC ( $80.9 \%$ vs $54.4 \%, \mathrm{p}<0.001)$. The main reasons for hospitalization were disease activity, infections, need for surgery, intravenous infusion of biological medication, and/or the need for additional exams or procedures in a hospital environment. Table 2 summarizes the clinical profile of this population.

\section{Crohn's Disease}

Most CD patients were diagnosed between 17 and 40 years of age, with a mean age of $32 \pm 14.5$ years. IIeocolonic involvement, inflammatory behavior (nonstricturing, nonpenetrating), and absence of perianal disease 
Table 2 Clinical Profile of Inflammatory Bowel Disease Patients in São Paulo City, Brazil

\begin{tabular}{|c|c|c|c|c|}
\hline & Total $(n=658)$ & $C D(n=303)$ & UC $(n=355)$ & $\mathbf{p}$ \\
\hline $\begin{array}{l}\text { Disease duration (years) } \\
\text { Mean } \pm \text { SD }\end{array}$ & $9.8 \pm 8.4$ & $10.6 \pm 9.2$ & $9.2 \pm 7.7$ & $0.029 *$ \\
\hline $\begin{array}{l}\text { Diagnostic delay (months) } \\
\text { Median (QI-Q3) } \\
\text { Missing data (n) }\end{array}$ & $\begin{array}{c}13(5-38) \\
168\end{array}$ & $\begin{array}{c}20(6.5-48) \\
62\end{array}$ & $\begin{array}{c}\text { II }(4-29) \\
106\end{array}$ & $<0.001 *$ \\
\hline & & n (\%) & & \\
\hline $\begin{array}{l}\text { Family history of IBD } \\
\text { Yes } \\
\text { Missing data }\end{array}$ & $\begin{array}{c}49(8.2) \\
58\end{array}$ & $\begin{array}{c}26(9.4) \\
27\end{array}$ & $\begin{array}{c}23(7.1) \\
31\end{array}$ & 0.358 \\
\hline $\begin{array}{l}\text { Hospitalization } \\
\text { At least I since diagnosis }\end{array}$ & $438(66.6)$ & 245 (80.9) & $193(54.4)$ & $<0.001 *$ \\
\hline $\begin{array}{l}\text { Extraintestinal manifestations } \\
\text { Joint } \\
\text { Oral } \\
\text { Skin } \\
\text { Ocular } \\
\text { Hepatobiliary disease }\end{array}$ & $\begin{array}{l}326(49.5) \\
71(10.8) \\
31(4.7) \\
29(4.4) \\
26(4)\end{array}$ & $\begin{array}{l}153(50.5) \\
44(14.5) \\
17(5.6) \\
16(5.3) \\
7(2.3)\end{array}$ & $\begin{array}{l}173(48.7) \\
27(7.6) \\
14(3.9) \\
13(3.7) \\
19(5.4)\end{array}$ & $\begin{array}{l}0.652 \\
0.004^{*} \\
0.314 \\
0.313 \\
0.046^{*}\end{array}$ \\
\hline $\begin{array}{l}\text { Pharmacological treatment since diagnosis } \\
\text { Corticosteroids } \\
\text { Salicylates } \\
\text { Immunomodulators } \\
\text { Biologics }\end{array}$ & $\begin{array}{l}498(75.7) \\
621(94.4) \\
406(61.7) \\
236(35.4)\end{array}$ & $\begin{array}{l}230(75.9) \\
267(88.1) \\
237(78.2) \\
170(56.1)\end{array}$ & $\begin{array}{l}268(75.5) \\
354(99.7) \\
169(47.6) \\
66(18.6)\end{array}$ & $\begin{array}{l}0.902 \\
<0.00 I^{*} \\
<0.00 I^{*} \\
<0.00 I^{*}\end{array}$ \\
\hline $\begin{array}{l}\text { Surgical Treatment } \\
\text { At least I IBD-related surgery }\end{array}$ & $176(26.7)$ & $160(52.8)$ & $16(4.5)$ & - \\
\hline
\end{tabular}

Notes: Quantitative variables: Student's $t$-test (normal distribution) and Mann-Whitney test (non-normal distribution); categorical variables: $\chi^{2}$ test; ${ }^{\mathrm{p}}<0.05=$ statistical significance. IBD-related surgery: CD: abdominal or perianal procedures due to complications of disease; UC: partial or total colectomy.

Abbreviations: CD, Crohn's disease; UC, ulcerative colitis; SD, standard deviation; (QI-Q3), interquartile range.

were the most common features. Perianal disease (fistula and/or perianal abscess) was found in $30 \%$ of the CD patients, regardless of the inflammatory, stricturing, or penetrating behavior (Table 3).

Patients with stricturing (B2), penetrating (B3), or associated perianal disease were younger, had a longer illness duration and a greater need for hospitalization, surgeries due to IBD, corticosteroids, immunomodulators, and biological drugs than patients with uncomplicated behavior (B1 without perianal disease). There was no statistical difference regarding gender, smoking habit, and use of salicylates (Table 4).

\section{Ulcerative Colitis}

Most patients had extensive colitis (E3) and were diagnosed between 17 and 40 years of age (A2). The mean age at diagnosis was $35.3 \pm 14.9$ years, with a statistically significant difference in the mean age compared to $\mathrm{CD}$ patients $(32 \pm 14.5$ years, $\mathrm{p}=0.004)$ (Table 3$)$.

Patients with extensive colitis were younger at diagnosis than those with left-sided UC. They had more frequent hepatobiliary involvement, a higher incidence of smoking at diagnosis, a greater need for hospitalization due to IBD, treatment with immunomodulators, and biological drugs compared to patients with left-sided UC and proctitis. There was no significant difference in terms of disease duration, sex, toxic megacolon, need for colectomy, use of corticosteroids, and salicylates (Table 5).

Eight patients were diagnosed with toxic megacolon $(2.3 \%)$, two of whom required surgery. None of the patients died from that complication in this series. Six patients $(1.7 \%)$ had a simple perianal fistula, attributed to inflammatory activity. Among the seven patients with colorectal cancer, five (1.4\% of UC patients) had a neoplastic stricture. 
Table 3 Montreal Classification of Inflammatory Bowel Disease Patients in São Paulo City, Brazil

\begin{tabular}{|c|c|c|c|}
\hline \multicolumn{2}{|c|}{ Montreal Classification } & \multirow{4}{*}{$\begin{array}{c}C D(n=303) \\
35(11.6) \\
185(61.1) * \\
83(27.4)\end{array}$} & \multirow{4}{*}{$\begin{array}{c}\text { UC }(n=355) \\
34(9.6) \\
197(55.5) * \\
124(34.9)\end{array}$} \\
\hline Age at diagnosis $(\mathrm{A})$ & Al ( $\leq 16$ years old $)$ & & \\
\hline & A2 (17-40 years old) & & \\
\hline & A3 (>40 years old) & & \\
\hline \multirow[t]{5}{*}{ Disease location (L) } & LI (terminal ileum) & $63(20.8)$ & - \\
\hline & L2 (colon) & $59(19.5)$ & - \\
\hline & L3 (ileocolon) & 145 (47.9)* & - \\
\hline & L4 (upper GI) & $20(6.6)$ & - \\
\hline & $\mathrm{LI}, \mathrm{L} 2$ or L3 + L4 & $16(5.3)$ & \\
\hline \multirow[t]{3}{*}{ Disease extent $(E)$} & EI (proctitis) & - & $42(11.8)$ \\
\hline & E2 (left-sided colitis) & - & $134(37.8)$ \\
\hline & E3 (extensive colitis) & - & $179(50.4) *$ \\
\hline \multirow[t]{6}{*}{ Disease behavior (B) } & BI (nonstricturing, nonpenetrating) & $90(29.7) *$ & - \\
\hline & BIp (perianal disease modifier) & $37(12.2)$ & - \\
\hline & B2 (stricturing) & $66(21.8)$ & - \\
\hline & B2p (perianal disease modifier) & $27(8.9)$ & - \\
\hline & B3 (penetrating) & $56(18.5)$ & - \\
\hline & B3p (perianal disease modifier) & $27(8.9)$ & - \\
\hline
\end{tabular}

Notes: Test of equal proportions for each group and disease; ${ }^{*} \mathrm{p}<0.05=$ statistical significance.

Abbreviations: CD, Crohn's disease; UC, ulcerative colitis; GI, gastrointestinal tract.

Table 4 Comparison Between Inflammatory Behavior of Crohn's Disease without Perianal Disease (BI) and Those with Complications (Strictures, Fistulas or Perianal Disease - B2, B3 or Bxp)

\begin{tabular}{|c|c|c|c|}
\hline & $\begin{array}{c}\text { CD - Inflammatory Behavior and No } \\
\text { Perianal Disease } \\
(B I) \\
(n=90)\end{array}$ & $\begin{array}{l}\text { CD with Strictures, Fistulas or } \\
\text { Perianal Disease } \\
\text { (B2, B3 or Bxp) } \\
(n=213)\end{array}$ & $\mathbf{p}$ \\
\hline Age at diagnosis (mean $\pm S D$ ) & $33.3 \pm 16.4$ & $31.4 \pm 13.6$ & $0.023 *$ \\
\hline Duration of disease (mean $\pm S D$ ) & $7.7 \pm 7.5$ & $11.8 \pm 9.5$ & $<0.00 I^{*}$ \\
\hline Female (n, \%) & $46(5 \mathrm{I} . \mathrm{I})$ & $106(49.8)$ & 0.830 \\
\hline Smoking habit at diagnosis of $C D(n, \%)$ & $18(20)$ & $53(24.9)$ & 0.209 \\
\hline Hospitalization (n, \%) & $53(58.9)$ & $192(90.1)$ & $<0.001 *$ \\
\hline Salicylates (n, \%) & $84(93.3)$ & $183(85.9)$ & 0.068 \\
\hline Corticosteroids (n, \%) & $59(65.6)$ & I7| (80.3) & $0.006 *$ \\
\hline Immunomodulators (n, \%) & $47(52.2)$ & $190(89.2)$ & $<0.00 I^{*}$ \\
\hline Biologics (n, \%) & $22(24.4)$ & $148(69.5)$ & $<0.00 I^{*}$ \\
\hline At least I IBD-related surgery $(n, \%)$ & $10(I I . I)$ & $150(70.4)$ & $<0.001 *$ \\
\hline
\end{tabular}

Notes: Quantitative variables: Student's $t$-test (normal distribution); categorical variables: $\chi^{2}$ test; ${ }^{*} p<0.05=$ statistical significance. IBD-related surgery: CD abdominal or perianal procedures due to complications of disease;

Abbreviations: CD, Crohn's disease; SD, standard deviation; n, number of patients; Bxp, BI, B2, or B3 with perianal disease.

\section{Pharmacological and Surgical Treatments}

More UC patients used salicylates (oral and/or rectal) than those with $\mathrm{CD}$, while, among those with $\mathrm{CD}$, the use of immunomodulators and biological drugs prevailed. Both UC and CD patients used corticosteroids (oral and/or intravenous), and there was no statistical difference between them (Table 2).
Considering only the patients who had medical consultation in the last five years (CD: 227 and UC:260) and the medications in use at the last medical appointment, $70.9 \%$ of those with $\mathrm{CD}$ were taking immunomodulators and/or biological drugs, and this percentage was significantly higher when compared to individuals with UC, during the same period $(28 \%, \mathrm{p}<0.001)$. Salicylates 
Table 5 Comparison Between Patients According to the Extension of Ulcerative Colitis

\begin{tabular}{|c|c|c|c|c|c|}
\hline & & $\begin{array}{l}\text { Proctitis (EI) } \\
\qquad(n=42)\end{array}$ & $\begin{array}{l}\text { Left-Side Colitis (E2) } \\
\qquad(n=134)\end{array}$ & $\begin{array}{l}\text { Extensive Colitis (E3) } \\
\qquad(n=179)\end{array}$ & $\mathbf{P}$ \\
\hline \multirow{3}{*}{\multicolumn{2}{|c|}{$\begin{array}{l}\text { Age at diagnosis }(\text { mean } \pm S D) \\
\text { Duration of disease }(\text { mean } \pm S D) \\
\text { Female }(n, \%)\end{array}$}} & $35 \pm 10.7$ & $39.8 \pm 15.2$ & $32.9 \pm 15.4$ & $<0.00 I^{* a}$ \\
\hline & & $8.6 \pm 8.6$ & $8.9 \pm 7.2$ & $9.5 \pm 7.7$ & 0.703 \\
\hline & & $29(69)$ & $88(65.7)$ & $102(57)$ & 0.170 \\
\hline \multirow{2}{*}{$\begin{array}{l}\text { Smoking habit at diagnosis } \\
\text { of US }\end{array}$} & Former smoker & $8(19.5)$ & $34(25.8)$ & $26(14.6)$ & \multirow[t]{2}{*}{$0.028^{*}$} \\
\hline & Smoker & $2(4.9)$ & $18(13.6)$ & $33(18.5)$ & \\
\hline \multicolumn{2}{|c|}{ Hepatobiliary extraintestinal manifestation (n, \%) } & I (2.4) & $\mathrm{I}(0.7)$ & $17(9.5)$ & $0.002 *$ \\
\hline \multicolumn{2}{|l|}{ Hospitalization (n, \%) } & $8(19)$ & $67(50)$ & $118(65.9)$ & $<0.001 *$ \\
\hline \multicolumn{2}{|l|}{ Salicylates (n, \%) } & $42(100)$ & $133(99.3)$ & $179(100)$ & 0.437 \\
\hline \multicolumn{2}{|l|}{ Corticosteroids (n, \%) } & $27(64.3)$ & $104(77.6)$ & $137(76.5)$ & 0.194 \\
\hline \multicolumn{2}{|l|}{ Immunomodulators (n, \%) } & II (26.2) & $60(44.8)$ & $98(54.7)$ & $0.003^{*}$ \\
\hline \multicolumn{2}{|l|}{ Biologics (n, \%) } & $0(0)$ & $22(16.4)$ & $44(24.6)$ & $0.001 *$ \\
\hline \multicolumn{2}{|l|}{ Colectomy (n, \%) } & $\mathrm{I}(2.4)$ & $4(3)$ & II (6.I) & 0.327 \\
\hline \multicolumn{2}{|l|}{ Toxic megacolon (n, \%) } & $0(0)$ & $3(2.2)$ & $5(2.8)$ & $0.882^{b}$ \\
\hline \multicolumn{2}{|l|}{ Colorectal Cancer (n, \%) } & I (2.4) & $3(2.2)$ & $3(1.7)$ & $0.875^{b}$ \\
\hline
\end{tabular}

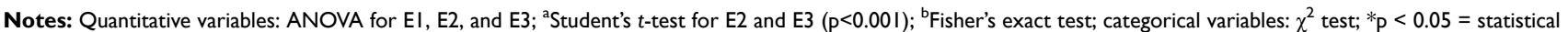
significance.

Abbreviations: UC, ulcerative colitis; SD, standard deviation; n, number of patients.

continued to be the predominant therapy in UC patients (78.1\% vs $17.2 \%$ in $\mathrm{CD}$ patients, $\mathrm{p}<0.001)$, with a lower frequency among $\mathrm{CD}$ patients in the last 5 years, compared to the total period of follow-up $(267 / 303,88.1 \%)$. Greater use of corticosteroids was also observed among UC patients $(11.9 \%$ vs $6.6 \%$ with $\mathrm{CD} \mathrm{p}=0.045)$, whereas 44 (19.4\%) CD patients and 34 (13.1\%) UC patients were not under medical treatment on the last consultation.

One hundred and sixty patients (52.8\%) with CD underwent surgery related to the disease at some time during their follow-up: 92 (57.5\%) abdominal surgery, 34 $(21.3 \%)$ perianal surgery, and $34(21.3 \%)$ had both types of intervention. Sixteen UC patients $(4.5 \%)$ underwent colectomy between 1996 and 2017, and 5 of them were due to colorectal cancer.

\section{Discussion}

In Brazil, as well as in other developing countries in Latin America, few epidemiological studies include the whole population, as no database unifies medical records across the country. ${ }^{19}$ Therefore, clinical and epidemiological data are obtained by analyzing medical records of patients followed up in a referral center for IBD care or through highcost medication pharmacy records. ${ }^{15}$ However, despite having a more significant population reach, clinical data from pharmacy records are less accurate. This data is relevant to understand the IBD population profile and to support the implementation of policies related to these patients' care. In São Paulo city, regardless of a few IBD referral centers, there are no recent publications with clinical and epidemiological profile descriptions of IBD patients obtained through medical records analysis. The present study was based on data from medical records of a referral center and included a larger number of cases compared to other studies carried out with similar methods throughout the country.

The limited access to healthcare considerably delays the time between symptom onset and diagnosis, and this may be responsible for a higher frequency of complications, need for surgery, and worse quality of life rates. ${ }^{19-22}$ In developed countries, more than $75 \%$ of patients are diagnosed in less than 12 months, with a longer time observed for those with CD. ${ }^{20-22}$ Low prevalence of IBD in Brazil, limited access to health professionals with expertise and diagnostic tools, increase this gap, and are the possible reasons to the higher diagnostic delay in this study. These findings are similar to those reported in other Brazilian publications. ${ }^{23-25}$

The present report showed a predominance of patients with UC. A similar finding was described by Gasparini et al in the state of São Paulo, who registered $53.84 \%$ of cases of $\mathrm{UC}$ and $46.16 \%$ of $\mathrm{CD}^{16}$ This dominancy was also observed in other epidemiological studies in Brazil ${ }^{17,23}$ and worldwide. ${ }^{10,19,26}$ However, it should be noted that there was an increase in the incidence of $\mathrm{CD}$ over the years in developed countries, reaching levels higher than 
those of UC in North America and in some European countries. $^{10,13,27}$ A recent systematic review showed the ratio of $\mathrm{UC}: \mathrm{CD}$ exceeding 1 in all regions throughout Latin America and the Caribbean except for Brazil. ${ }^{28}$

IBD occurs predominantly in young adults. The average age of patients in this analysis (44 years) was similar to that found in other national studies. ${ }^{16,17,29-32}$ The age at diagnosis of IBD ranged between 30 and40 years old, and the average for $\mathrm{CD}$ patients (32 years) was lower than that for UC patients (35.3 years). Parente et al, in an epidemiological study carried out in Piaui, a state that has a lower index of industrialization and urbanization than São Paulo, found a similar mean age at diagnosis $(32.9 \pm 13.6$ years for $\mathrm{CD}$ and $36.8 \pm 14.8$ years for UC). ${ }^{23}$ In developed countries, such as the United States and Canada, the highest incidence of CD was found in individuals between 20 and 29 years of age, and of UC between 20 and 39 years of age. ${ }^{27,33}$ This difference between Brazil and developed countries in terms of age, in addition to geographic and cultural factors, may also be related to diagnostic delay. $^{22}$

It is known that the Brazilian population is multiracial. According to the 2010 Brazilian Census, São Paulo city population had approximately $60 \%$ Caucasian, 30\% mixed-race, 6.5\% African descent, 2\% Asian descent, and $0.1 \%$ Indigenous populations. ${ }^{34}$ Ethnicity in this study was obtained from medical records, and the findings were similar to the census data, except for a lower percentage of the Asian descent population (0.4\%) and the absence of Indigenous people. This proportion differs from that found by Parente et al in Piaui and Santana et al in Bahia, where the percentage of the mixed-race population was higher than the Caucasians. ${ }^{23,35}$ This difference is due to the influence of São Paulo's colonization by Europeans. Molodecky et al, in a 2012 systematic review and $\mathrm{Ng}$ et al in 2017, reported a higher incidence of IBD among the Caucasian population, as well as increasing in Asian and Hispanic populations. ${ }^{10,13}$

Genetic predisposition is part of the pathogenesis of IBD. ${ }^{4}$ The prevalence of IBD in patients' relatives, in developed countries, varies from $7 \%$ to $12 \%$, with predominance among $\mathrm{CD}$ patients and concordance between the types of IBD. ${ }^{36-38}$ In Mexico, only $6.78 \%$ of UC patients reported a family history of $\mathrm{IBD} .{ }^{39}$ According to Brazilian epidemiological surveys, the prevalence of a family history was 11.4 to $16 \%$ among patients with $\mathrm{CD}$ and 7.9 to $9.3 \%$ among those with UC. ${ }^{23,24,40,41}$ In our study, $8.2 \%$ of individuals with IBD had a family history of these diseases, with a reasonable concordance regarding the type of IBD among relatives.

There is no consensus about the most common location and behavior of CD: ileocolonic disease (L3) (17 to 58\%) and terminal ileum (L1) (11 to $58 \%$ of cases) are the most common location, with a lower percentage of involvement of the upper gastrointestinal tract (L4), regardless of the association with other sites. ${ }^{24,27,29,31,32,44-49}$ Inflammatory behavior (non-stricturing and non-penetrating) is the most reported (42 to $81 \%),{ }^{29,32,41,43,44,47,48}$ with greater proportions when the disease duration was shorter. ${ }^{41,47,48}$ Studies have shown perianal disease in 10 to $46.4 \%$ of patients. $^{23,29,41-44,46,48}$ Our findings are in accordance with those described in medical literature: most common involvement of the ileocolonic site $(47.9 \%)$, inflammatory behavior (41.9\%), and perianal involvement in $30 \%$ of patients. Individuals with strictures, fistulas, or perianal disease, as expected, had a longer disease duration compared with those with inflammatory behavior.

Unlike the stability noted in the location of CD over time, it is common to notice the progression or regression of the extent of inflammation in UC when following up. Therefore, it is recommended to consider the highest recorded involvement of the disease. ${ }^{18}$ In this study, it was found that half of the patients had extensive colitis (E3) as the maximum extent, and the mean duration of their disease was 10 years, with no statistical difference regarding the follow-up period of cases with lesser extent of inflammation. A higher proportion of patients with extensive colitis was also reported by other surveys, ${ }^{26,29,30,39,43,49}$ although in some, left-sided colitis (E2) was predominant. ${ }^{23,31,32,45,49-51}$

There is evidence that the extent of UC is related to the need for hospitalization and colectomy, as well as age at diagnosis, risk of colorectal cancer, and association with primary sclerosing cholangitis. ${ }^{18,52}$ In this study population, patients with extensive colitis, in fact, were the youngest at diagnosis, with higher number of cases associated with primary sclerosing cholangitis, hospitalizations, and greater need for immunomodulators and biologic treatment. Colectomy and complications such as toxic megacolon were also more prevalent among these patients. However, due to its small number, it was not possible to verify a statistical difference between them.

Several factors lead IBD patients to hospitalization: the need for diagnostic tests, disease activity, and surgery. ${ }^{7}$ Studies have shown various hospitalization rates worldwide, which were higher in CD than in UC. ${ }^{7,19,53}$ In South 
America, the highest rates are in Colombia (CD: 75\% and UC: $42.9 \%$ ) and Peru (CD: $75 \%$ and UC: $51.8 \%){ }^{28}$ Among the cases of this study, there was a high need for hospitalization due to IBD during 20 years of follow-up, and among CD patients $(80.9 \%)$ compared with UC patients $(54.4 \%)$. This high rate reflects a greater number of patients with extensive $\mathrm{UC}$ and complicated $\mathrm{CD}$, with strictures or fistulas.

The treatment of IBD has undergone significant changes in the last 20 years, since the introduction of biologic therapy, initially for $\mathrm{CD}$ treatment, and years later, for UC. ${ }^{54}$ Studies that demonstrated the ineffectiveness of salicylates use for $\mathrm{CD}^{55,56}$ led to the recent reformulation of the treatment consensus for this disease, reserving salicylate prescription only in mild colonic presentation. $^{53,57}$ This new therapeutic orientation was reflected in this study, in the expressive reduction in the proportion of CD patients that used salicylates (88.1\%) compared to the proportion in the last five years followup $(17.2 \%)$.

From the diagnosis to the last consultation of all those included, many $\mathrm{CD}$ patients required treatment with immunomodulators and biologics. This finding is in line with the most current recommendations, in which these classes of drugs are necessary for disease control. ${ }^{53,57,58}$ In Brazilian studies, the use of immunomodulators in $\mathrm{CD}$ ranged from 35.3 to $80.4 \%$, and of biologics, between 8.5 to $53.8 \% .^{30,31,41,43}$ In this study, we found similar or higher use of immunomodulators (78.2\%) and higher use of biologics (56.1\%) than those described by other Brazilian publications. This fact may reflect the greater severity of CD and more expanded treatment access.

Regarding UC treatment, salicylates were the most prescribed therapy, as almost $100 \%$ of patients had used these drugs orally, topically, or both ways. The use of immunomodulators and biologics to treat UC was $47.6 \%$ and $18.6 \%$, respectively, higher than the rates found in other Brazilian reports (19.4 to $29.1 \%$ and 1.5 to $10.8 \%)^{24,30,31,43}$ This data also reflects a greater severity of the disease in our patients.

A systematic review that included 30 studies from 20 countries, involving 10,161 patients with $\mathrm{CD}$ and 11,335 with UC, between 1955 and 2011, concluded that the cumulative incidence of abdominal surgery in 10 years for $\mathrm{CD}$ and $\mathrm{UC}$ patients was $46.6 \%$ and $15.6 \%$, respectively, which reduced to less than $40 \%$ and $11.9 \%$ for CD and $\mathrm{UC}$, respectively, considering only the diagnosis made after $1980 .^{59}$ It is believed that early diagnosis and introduction of immunomodulators and biologic therapy in moderate to severe cases have recently contributed to reducing the need for surgery. ${ }^{20,21,59,60}$ A large number of surgeries for CD were observed in this study series, similar to that reported in patients diagnosed before 1980 , from the aforementioned meta-analysis. We believe that this high percentage may be related to the delayed diagnosis and initiation of efficacious therapy. The percentage of colectomy in UC (4.5\%) was lower than that found in the meta-analysis by Frolkis et al, ${ }^{59}$ but similar to that described in another Brazilian study, involving $267 \mathrm{UC}$ patients, in which only $3.4 \%$ of the patients underwent colectomy. $^{24}$

The present study has major limitations related to data collection (retrospective cross-sectional analysis of data from medical records), such as the lack of data for some variables, as reported, as well as the description of disease severity and the temporal relationship between the drug and surgical treatments. Taking this single-center analysis into consideration, it is impossible to precisely calculate the actual populational prevalence and incidence of IBD in a vast country with several IBD referral units such as Brazil. However, we believe that, due to the large number of patients included, of a population not yet studied, our research should help to describe the clinical and epidemiological profile of patients with inflammatory bowel diseases in São Paulo city. Prospective, multicenter, population-based studies are required to understand the clinical and epidemiological data better. We believe that the advent of electronic medical records and a national patient registry will be decisive in obtaining robust data.

\section{Conclusion}

In conclusion, this is the first study addressing clinical and demographic profile in the population of São Paulo city as far as we know. Most clinical and demographic data are similar to developed countries' reports, notwithstanding the UC predominance over CD. Even in a highly urbanized area and despite the increasing incidence of IBD in Brazil, the diagnostic delay is still a big concern, leading to more complicated diseases. The higher proportion of complicated $\mathrm{CD}$ and extensive $\mathrm{UC}$, resulted in a greater need for health care resources in this cohort, such as biological treatment, hospitalization, and surgery. We believe that this result can indirectly raise consciousness about the importance of investing in disease awareness, access to diagnostic exams, and therapy within the window of opportunity to avoid/prevent complications and disability. 


\section{Acknowledgments}

The authors wish to express their gratitude to all participants of this protocol.

\section{Author Contributions}

All authors made a significant contribution to the work reported, whether that is in the conception, study design, execution, acquisition of data, analysis and interpretation, or in all these areas; took part in drafting, revising or critically reviewing the article; gave final approval of the version to be published; have agreed on the journal to which the article has been submitted; and agree to be accountable for all aspects of the work. The authors declare no conflicts of interest.

\section{Disclosure}

This study was performed at São Paulo Hospital Universidade Federal de São Paulo - Escola Paulista de Medicina - UNIFESP/EPM, São Paulo, SP, Brazil. This study was financed in part by the Coordenação de Aperfeiçoamento de Pessoal de Nível Superior - Brasil (CAPES) - Finance Code 001. Dr Tarcia Nogueira Ferreira Gomes report grants from Coordenação de Aperfeiçoamento de Pessoal de Nível Superior - Brasil (CAPES), during the conduct of the study and personal fees from Janssen Pharmaceutical Company, outside the submitted work. The authors report no other conflicts of interest in this work.

\section{References}

1. Abraham $\mathrm{C}$, Cho JH. Inflammatory bowel disease. $N$ Engl J Med. 2009;361(21):2066-2078. doi:10.1056/NEJMra0804647

2. Khor B, Gardet A, Xavier RJ. Genetics and pathogenesis of inflammatory bowel disease. Nature. 2011;474(7351):307-317. doi:10.1038/ nature 10209

3. Zhang Y-Z. Inflammatory bowel disease: pathogenesis. World $J$ Gastroenterol. 2014;20(1):91-99. doi:10.3748/wjg.v20.i1.91

4. Turpin W, Goethel A, Bedrani L, Croitoru K. Determinants of IBD heritability: genes, bugs, and more. Inflamm Bowel Dis. 2018;24 (6):1133-1148.

5. Strohl M, Gonczi L, Kurt Z, Bessissow T, Lakatos PL. Quality of care in inflammatory bowel diseases: what is the best way to better outcomes? World J Gastroenterol. 2018;24(22):2363-2372.

6. Gibson PR, Vaizey C, Black CM, et al. Relationship between disease severity and quality of life and assessment of health care utilization and cost for ulcerative colitis in Australia: a cross-sectional, observational study. J Crohn's Colitis. 2014;8(7):598-606.

7. Burisch J, Jess T, Martinato M, Lakatos PL. ECCO - EpiCom. The burden of inflammatory bowel disease in Europe. J Crohn's Colitis. 2013;7(4):322-337.

8. de SB, Fróes R, Carvalho ATP, De V, Carneiro AJ. The socio-economic impact of work disability due to inflammatory bowel disease in Brazil. Eur J Heal Econ. 2017;19(3):463-470.
9. Parra RS, Chebli JM, Amarante HM, et al. Quality of life, work productivity impairment and healthcare resources in inflammatory bowel diseases in Brazil. World J Gastroenterol. 2019;25(38):58625882 .

10. Ng SC, Shi HY, Hamidi N, et al. Worldwide incidence and prevalence of inflammatory bowel disease in the 21 st century: a systematic review of population-based studies. Lancet. 2017;390(10114):27692778. doi:10.1016/S0140-6736(17)32448-0

11. Kaplan GG. The global burden of IBD: from 2015 to 2025. Nat Rev Gastroenterol Hepatol. 2015;12(12):720-727. doi:10.1038/nrgastro. 2015.150

12. Rocchi A, Benchimol EI, Bernstein CN, et al. Inflammatory bowel disease: a Canadian burden of illness review. Can J Gastroenterol. 2012;26(11):811-817. doi:10.1155/2012/984575

13. Molodecky NA, Soon IS, Rabi DM, et al. Increasing incidence and prevalence of the inflammatory bowel diseases with time, based on systematic review. Gastroenterology. 2012;142(1):46-54.e42.

14. Souza AMD, Resende SS, Sousa TND, Brito CFAD. A systematic scoping review of the genetic ancestry of the Brazilian population. Genet Mol Biol. 2019;42(3):495-508. doi:10.1590/1678-4685-gmb2018-0076

15. Moreira A, Lobato LF, Souza HS. IBD Epidemiology: What is Going on in the Developing World? Results from 163,000 Patients. San Diego, CA: AGA Abstracts; 2019:S-73. Available from: https:// www.gastrojournal.org/article/S0016-5085(19)36968-9/pdf. Accessed February 26, 2021.

16. Galhardi Gasparini R, Sassaki LY, Saad-Hossne R. Inflammatory bowel disease epidemiology in São Paulo State, Brazil. Clin Exp Gastroenterol. 2018;11:423-429. doi:10.2147/CEG.S176583

17. Victoria CR, Sassak LY, Nunes HRDC. Incidence and prevalence rates of inflammatory bowel diseases, in midwestern of São Paulo State, Brazil. Arq Gastroenterol. 2009;46(1):20-25. doi:10.1590/ S0004-28032009000100009

18. Silverberg MS, Satsangi J, Ahmad T, et al. Toward an integrated clinical, molecular and serological classification of inflammatory bowel disease: report of a working party of the 2005 Montreal world congress of Gastroenterology. Can J Gastroenterol. 2005;19 (suppl a):5A-36A. doi:10.1155/2005/269076

19. Calderón M, Minckas N, Nuñez S, Ciapponi A. Inflammatory bowel disease in Latin America: a systematic review. Value Heal Reg Issues. 2018;17c:126-134.

20. Schoepfer AM, Dehlavi M-A, Fournier N, et al. Diagnostic Delay in Crohn's Disease Is Associated With a Complicated Disease Course and Increased Operation Rate. Am J Gastroenterol. 2013;108 (11):1744-1753. doi:10.1038/ajg.2013.248

21. Zaharie R, Tantau A, Zaharie F, et al. Diagnostic delay in Romanian patients with inflammatory bowel disease: risk factors and impact on the disease course and need for surgery. J Crohn's Colitis. 2016;10 (3):306-314. doi:10.1093/ecco-jcc/jjv215

22. Cantoro L, Di Sabatino A, Papi C, et al. The time course of diagnostic delay in inflammatory bowel disease over the last sixty years: an Italian multicentre study. J Crohn's Colitis. 2017;11(8):975-980. doi:10.1093/ecco-jcc/jjx041

23. Parente JM, Coy CS, Campelo V. Inflammatory bowel disease in an underdeveloped region of Northeastern Brazil. World $J$ Gastroenterol. 2015;21(4):1197-1206. doi:10.3748/wjg.v21.i4.1 197

24. da Silva BC, Lyra AC, Mendes CMC, et al. The demographic and clinical characteristics of ulcerative colitis in a Northeast Brazilian population. Biomed Res Int. 2015;2015:1-8. doi:10.1155/2015/35 9130

25. Nóbrega VG, Silva INDN, Brito BS, Silva J, Silva MCMD, Santana GO. Silva IN de N, Brito BS, Silva J, da Silva MCM, Santana GO. The onset of clinical manifestations in inflammatory bowel disease patients. Arq Gastroenterol. 2018;55(3):290-295. doi:10.1590/s00042803.201800000-73 
26. Yamamoto-Furusho J, Sarmiento A, Toledo-Mauriño J, et al. P839 Clinical and sociodemographical characteristics of inflammatory bowel disease in Mexico: multicentric nation-wide study (EPIMEXIBD). J Crohn's Colitis. 2018;12(Suppl supplement_1):S540-S540. doi:10.1093/ecco-jcc/jjx180.966

27. Bitton A, Vutcovici M, Patenaude VVV, Sewitch M, Suissa S, Brassard P. Epidemiology of Inflammatory Bowel Disease in Québec. Inflamm Bowel Dis. 2014;20(10):1770-1776. doi:10.1097/ MIB.0000000000000162

28. Kotze PG, Underwood FE, Damião AOMC, et al. Progression of inflammatory bowel diseases throughout Latin America and the Caribbean: a systematic review. Clin Gastroenterol Hepatol. 2020;18(2):304-312. doi:10.1016/j.cgh.2019.06.030

29. Dos Santos RMD, Carvalho ATP, Silva K, Sá SPC, Dos Santos AHD, Sandinha MR. Inflammatory Bowel Disease: outpatient Treatment Profile. Arq Gastroenterol. 2017;54(2):96-100. doi:10.1590/S00042803.201700000-01

30. Arantes JAV, Santos CHMD, Delfino BM. dos Santos CHM, Delfino $\mathrm{BM}$, et al. Epidemiological profile and clinical characteristics of patients with intestinal inflammatory disease. $J$ Coloproctology. 2017;37(4):273-278. doi:10.1016/j.jcol.2017.06.004

31. Kleinubing-Júnior H, Pinho MDSL, Ferreira LC, Bachtold GA, Merki A. Perfil dos pacientes ambulatoriais com doenças inflamatórias intestinais. ABCD. Arquivos Brasileiros De Cirurgia Digestiva. 2011;24(3):200-203. doi:10.1590/S0102-672020110003 00004

32. Souza MMD, Belasco AGS, Aguilar-Nascimento JED. Perfil epidemiológico dos pacientes portadores de doença inflamatória intestinal do estado de Mato Grosso. Revista Brasileira De Coloproctologia. 2008;28(3):324-328. doi:10.1590/S0101-9880200 8000300009

33. Kappelman MD, Rifas-Shiman SL, Kleinman K, et al. The prevalence and geographic distribution of Crohn's disease and ulcerative colitis in the United States. Clin Gastroenterol Hepatol. 2007;5 (12):1424-1429. doi:10.1016/j.cgh.2007.07.012

34. Instituto Brasileiro de Geografia e Estatística (IBGE). Censo 2010: universo: características da população e dos domicílios [Internet]; 2010. Available from: https://cidades.ibge.gov.br/brasil/sp/sao-paulo/ pesquisa/23/25888?detalhes=true. Accessed Jan 25, 2019.

35. Santana GO. Crohn's disease in one mixed-race population in Brazil. World J Gastroenterol. 2007;13(33):4489-4492. doi:10.3748/wjg. v13.i33.4489

36. Moller FT, Andersen V, Wohlfahrt J, Jess T. Familial risk of inflammatory bowel disease: a population-based cohort study 1977-2011. Am J Gastroenterol. 2015;110(4):564-571. doi:10.1038/ajg.2015.50

37. Childers RE, Eluri S, Vazquez C, Weise RM, Bayless TM, Hutfless S. Family history of inflammatory bowel disease among patients with ulcerative colitis: a systematic review and meta-analysis. J Crohn's Colitis. 2014;8(11):1480-1497. doi:10.1016/j.crohns.2014.05.008

38. Cabré E, Mañosa M, García-Sánchez V, et al. Phenotypic concordance in familial inflammatory bowel disease (IBD). Results of a nationwide IBD Spanish database. J Crohn's Colitis. 2014;8(7):654661. doi:10.1016/j.crohns.2013.12.005

39. Yamamoto-Furusho JK. Clinical epidemiology of ulcerative colitis in Mexico: a single hospital-based study in a 20-year period (19872006). J Clin Gastroenterol. 2009;43(3):221-224. doi:10.1097/ MCG.0b013e31817a76b4

40. Salgado VCL, Luiz RR, Boéchat NLF, et al. Risk factors associated with inflammatory bowel disease: a multicenter case-control study in Brazil. World J Gastroenterol. 2020;26:3611-3624.

41. de Barros KSC, Flores C, Harlacher L, Francesconi CFM. Evolution of clinical behavior in crohn's disease: factors associated with complicated disease and surgery. Dig Dis Sci. 2017;62(9):2481-2488.

42. Schwartz DA, Loftus E, Tremaine WJ, et al. The natural history of fistulizing Crohn's disease in Olmsted County, Minnesota. Gastroenterology. 2002;122(4):875-880.
43. Lima Martins A, Volpato RA, Zago-Gomes M. The prevalence and phenotype in Brazilian patients with inflammatory bowel disease. BMC Gastroenterol. 2018;18(1):87.

44. Torres UDS, Rodrigues JO, Junqueira MSG, Uezato S, Netinho JG. The Montreal classification for Crohn's disease: clinical application to a Brazilian single-center cohort of 90 consecutive patients. Arq Gastroenterol. 2010;47(3):279-284

45. Souza MHLP. Troncon LE de A, Rodrigues CM, et al. Evolução da ocorrência (1980-1999) da doença de Crohn e da retocolite ulcerativa idiopática e análise das suas características clínicas em um hospital universitário do sudeste do Brasil. Arq Gastroenterol. 2002;39(2):98105.

46. Hou JK, El-Serag H, Thirumurthi S. Distribution and manifestations of inflammatory bowel disease in Asians, Hispanics, and African Americans: a systematic review. Am J Gastroenterol. 2009;104 (8):2100-2109.

47. Thia KT, Sandborn WJ, Harmsen WS, Zinsmeister AR, Loftus EV. Risk Factors Associated With Progression to Intestinal Complications of Crohn's Disease in a Population-Based Cohort. Gastroenterology. 2010;139(4):1147-1155.

48. Cosnes J, Cattan S, Blain A, et al. Long-term evolution of disease behavior of Crohn's disease. Inflamm Bowel Dis. 2002;8(4):244-250.

49. Magro F, Rodrigues A, Vieira AI, et al. Review of the disease course among adult ulcerative colitis population-based longitudinal cohorts. Inflamm Bowel Dis. 2012;18(3):573-583.

50. Ungaro R, Mehandru S, Allen PB, Peyrin-Biroulet L, Colombel JF. Ulcerative colitis. Lancet. 2017;389:1756-1770.

51. Barreiro-de Acosta M, Magro F, Carpio D, et al. Ulcerative colitis in northern Portugal and Galicia in Spain. Inflamm Bowel Dis. 2010;16 (7):1227-1238.

52. Magro F, Gionchetti P, Eliakim R, et al. Third European evidencebased consensus on diagnosis and management of ulcerative colitis. Part 1: definitions, diagnosis, extra-intestinal manifestations, pregnancy, cancer surveillance, surgery, and ileo-anal pouch disorders. $J$ Crohn's Colitis. 2017;11(6):649-670.

53. Lichtenstein GR, Loftus EV, Isaacs KL, Regueiro MD, Gerson LB, Sands BE. ACG Clinical Guideline: management of Crohn's Disease in Adults. Am J Gastroenterol. 2018;113(4):481-517.

54. Amiot A, Peyrin Biroulet L. Current, new and future biological agents on the horizon for the treatment of inflammatory bowel diseases. Therap Adv Gastroenterol. 2015;8(2):66-82.

55. Lim W-C, Wang Y, MacDonald JK, Hanauer S. Aminosalicylates for induction of remission or response in Crohn's disease. Cochrane Database Syst Rev. 2016;7:CD008870.

56. Akobeng AK, Zhang D, Gordon M, MacDonald JK. Oral 5-aminosalicylic acid for maintenance of medically-induced remission in Crohn's disease. Cochrane Database Syst Rev. 2016;9:CD003715.

57. Gomollón F, Dignass A, Annese V, et al. 3rd European evidencebased consensus on the diagnosis and management of Crohn's disease 2016: part 1: diagnosis and medical management. J Crohn's Colitis. 2017;11(1):3-25.

58. Brazilian Study Group of Inflammatory Bowel Diseases. Consensus guidelines for the management of inflammatory bowel disease. Arq Gastroenterol. 2010;47(3):313-325.

59. Frolkis AD, Dykeman J, Negron ME, et al. Risk of surgery for inflammatory bowel diseases has decreased over time: a systematic review and meta-analysis of population-based studies. Gastroenterology. 2013;145(5):996-1006.

60. Argollo MC, Kotze PG, Spinelli A, Gomes TNF, Danese S. The impact of biologics in surgical outcomes in ulcerative colitis. Best Pract Res Clin Gastroenterol. 2018;32-33:79-87. 


\section{Publish your work in this journal}

Clinical and Experimental Gastroenterology is an international, peerreviewed, open access, online journal publishing original research, reports, editorials, reviews and commentaries on all aspects of gastroenterology in the clinic and laboratory. This journal is indexed on American Chemical Society's Chemical Abstracts Service (CAS).
The manuscript management system is completely online and includes a very quick and fair peer-review system, which is all easy to use. Visit http://www.dovepress.com/testimonials.php to read real quotes from published authors.

Submit your manuscript here: https://www.dovepress.com/clinical-and-experimental-gastroenterology-journal 